\title{
Glucose attenuates cold-induced impairment of delayed matching-to-sample performance in rats
}

\author{
STEPHEN T. AHLERS, DAVID SHURTLEFF, JOHN SCHROT, \\ JOHN R. THOMAS, and F. PAUL-EMILE \\ Naval Medical Research Institute, Bethesda, Maryland
}

\begin{abstract}
Administration of glucose has been shown to enhance performance in a variety of test situations in which memory is impaired by some amnestic treatment. In the present study, the effects of glucose were examined on a working-memory deficit produced when rats performed a delayed matching-to-sample (DMTS) task while being exposed to ambient cold air. In the DMTS task, the rats were required to respond on one of two levers cued by an illuminated light above the lever on the front wall of an operant chamber. Following a variable delay ranging from 1 to $16 \mathrm{sec}$, both lights were illuminated and the rats were required to correctly respond on the lever previously cued for a food reward. They responded on the back wall lever during the delay interval to prevent position bias. Glucose $(10-500 \mathrm{mg} / \mathrm{kg}$ ) or saline, administered (i.p.) in a mixed sequence, were given $1 \mathrm{~h}$ before a 75-min session in which the rats performed the DMTS task (180 trials). During test sessions, the ambient air temperature was either $23^{\circ} \mathrm{C}$ or $2^{\circ} \mathrm{C}$. Administration of glucose during exposure to $23^{\circ} \mathrm{C}$ did not systematically affect matching accuracy or other performance measures. In the rats pretreated with saline, exposure to $2^{\circ} \mathrm{C}$ produced a downward shift in the delay gradient in that matching accuracy was impaired at all delay intervals when compared with performance at $23^{\circ} \mathrm{C}$. Glucose produced dose-dependent improvement of matching accuracy with short, but not long, interpolated delays. Selective modulation of cold-induced impairment of working memory at the short delays suggests that glucose preferentially enhances stimulus acquisition during exposure to cold stress.
\end{abstract}

Glucose has been shown to enhance memory, alleviate memory deficits resulting from age-related decline, and reduce or reverse amnesia produced by pharmacological agents (see Gold, 1991, for a review). While a majority of studies demonstrating glucose enhancement of memory have focused on modulation of long-term memory, several reports have shown that glucose can also enhance short-term (working) memory. For example, Stone, Walser, Gold, and Gold (1991) demonstrated that pretreatment with 100 or $300 \mathrm{mg} / \mathrm{kg}$ glucose attenuated a decrement in alternation performance produced by the cholinergic muscarinic antagonist scopolamine and the opiate agonist morphine. Similarly, Ragozzino and Gold (1991) demonstrated that $100 \mathrm{mg} / \mathrm{kg}$ glucose attenuated an impairment of spontaneous alternation resulting from administration of the nicotinic cholinergic antagonist mecamylamine. Additional evidence of glucose enhance-

The authors gratefully acknowledge the input of Patricia M. Thomton. This research was supported by Naval Medical Research and Development Command Research and Technology Work Units 62233N MM33C30.004-1002 and 61153 MR04120.00D-1383. The opinions and assertions contained herein are those of the authors and are not to be construed as official or reflecting the views of the Navy Department or the Naval Service at large. The experiments reported herein were conducted according to the principles set forth in the Guide for the Care and Use of Laboratory Animals, Institute of Laboratory Animal Resources, National Research Council, DHHS Publication (NIH) 86-23-1985. Address correspondence to S. T. Ahlers, Thermal Stress/Adaptation Program, Naval Medical Research Institute, Bethesda, MD 20889-5607. ment of working memory has been reported in a recent study by Means and Fernandez (1992), in which 100 and $250 \mathrm{mg} / \mathrm{kg}$ of glucose significantly improved the acquisition of trial-specific information using a working-memory task.

The purpose of the present experiment was to determine if glucose would reverse a cold-induced deficit in working memory produced by exposing rats to the stress of cold air. Several studies have demonstrated impairment of short-term or working-memory processes in humans (Thomas, Ahlers, House, \& Schrot, 1989) and animals (Ahlers, Thomas, \& Berkey, 1991; Thomas, Ahlers, \& Schrot, 1991) exposed to moderately cold environments in which there was no decrease in colonic temperature. For example, Thomas et al. (1991) demonstrated that exposing rats to an ambient cold stress of $2^{\circ} \mathrm{C}$ while performing a delayed matching-to-sample (DMTS) task impaired matching accuracy at delays of 8 and $16 \mathrm{sec}$. Since accuracy at a 2 -sec delay interval was unimpaired by the cold stress, it was concluded that cold-induced impairment specifically decreased the ability to specifically retain stimulus information in working memory, since the initial encoding of the stimulus, as measured by accuracy at the shortest delay, was unaffected by cold stress. However, other studies have shown that similar exposure to cold stress can also produce a downward shift of the delay gradient in which accuracy at all of the delays is decreased (Ahlers et al., 1991). In these instances, the effect of cold stress would appear to impair stimulus acquisition. 
Although cold-induced impairment of working memory does not appear to involve a decrease in body temperature, a recent study by Ahlers et al. (1991) demonstrated that exposure to cold stress attenuates a $1^{\circ} \mathrm{C}$ increase in hippocampal temperature that normally occurs when rats perform the DMTS procedure at $23^{\circ} \mathrm{C}$. Although a definitive link between the reduction in temperature in the hippocampus and impaired performance during cold stress has not been established, these findings are consistent with cold-induced impairment of short-term memory resulting from the cooling of the specific brain regions that modulate working memory. Were this to be the case, exposure to cold stress may lead to a decrease in glucose-dependent metabolic activity in brain structures involved with the acquisition and retention of information (Destrade, Messier, Bontempi, Sif, \& Jaffard, 1992).

\section{METHOD}

\section{Subjects}

The subjects were 3 experimentally naive male Long-Evans rats, maintained over the course of the study at $85 \%$ of their free-feeding weight of approximately $340-360 \mathrm{~g}$. They were approximately 1 year of age at the beginning of the study. The rats were individually housed in hanging cages in an air-controlled unit. Water was available ad lib in the home cages.

\section{Apparatus}

The rats performed in a three-lever operant chamber, $24.1 \times$ $30.4 \times 26.6 \mathrm{~cm}$. Two response levers were mounted on the front wall, $5.0 \mathrm{~cm}$ above the grid floor and $3.8 \mathrm{~cm}$ from either of the side walls. A food tray was mounted $1.2 \mathrm{~cm}$ above the grid floor and in the center of the front wall, equidistant from each of the levers. The tray was connected by a short tube to a pellet feeder located behind the front wall, which could dispense 45-mg food pellets (BioServe Inc., Frenchtown, NJ). A small light with a white lens cover was mounted $5.0 \mathrm{~cm}$ above both the right and left levers. A third response lever with a light positioned above it was located on the back wall, $5.0 \mathrm{~cm}$ above the floor. A speaker placed behind the front wall was used for presentation of a $2800-\mathrm{Hz}$ tone at approximately $40 \mathrm{~dB}$. A houselight was mounted on the top of the front wall. All baseline and cold-exposure sessions were conducted with the rat cage housed inside a temperature-controlled environmental chamber with internal dimensions of $61.0 \times 71.1 \times 121.9 \mathrm{~cm}$. Experimental events were controlled and recorded by a microcomputer system.

\section{Procedure}

Initial training involved shaping the rats to barpress a single lever on the front wall when the light above the lever was illuminated. Over the course of approximately 4 months, the rats were gradually shaped to respond to chained elements of the matching procedure. Once performance was maintained at accuracy above $90 \%$ with no imposed delay in 180 trials, the delays were gradually introduced, starting with the 1- and 2-sec delays and finally introducing the 16-sec delay. The rats generally spent 6-8 weeks on the full task to reach stable performance.

Sessions were conducted 5 days per week (Monday-Friday) with sessions terminating after completion of 180 trials or $75 \mathrm{~min}$, whichever occurred first. The houselight was illuminated during all sessions. At the start of each trial, the correct lever was cued by illumination of the light over one of the two levers on the front wall. The rat was required to press the lever under the illuminated light. A response on the cued lever turned off the light and started a delay interval. A response on the noncued lever also turned off the light, but was followed by a $10-\sec$ intertrial interval and the start of the next trial. A trial occurrence was recorded only if the rat correctly responded on the cued lever. At the start of the delay, the light was illuminated over the single lever on the back wall. The delay lasted for $1,2,4,8$, or $16 \mathrm{sec}$. A random order of delay intervals was presented in each session, with the following constraints. Within a block of 10 trials, each delay appeared two times. Half of the trials at a particular delay interval began with the left light illuminated on the front wall and the other half began with the right light illuminated. No more than 2 trials with the same delay could occur consecutively. The first response on the back wall lever following the completion of the delay resulted in turning off the back wall light, sounding a $2800-\mathrm{Hz}$ tone, and illuminating both lights over the two front wall levers. Responding during the delay was maintained on a fixed-interval schedule corresponding to the nominal value of the delay. Maintenance of responding on the back wall lever prevented the development of position bias or the adoption of simple mediating response patterns, such as standing in front of the appropriate front wall lever. The fixed-interval requirement also ensured that the rat was always positioned centrally in the back of the chamber at the termination of the delay interval. Following illumination of the two front wall lights and tone onset, a response on the previously cued front wall lever was recorded as a correct matching response. A correct matching response produced a food pellet and turned off both front panel lights. If a response was made on the previously noncued front panel lever (an incorrect matching response), both front panel lights were turned off. Following either a correct or an incorrect matching response, a 10 -sec intertrial interval preceded the beginning of the next trial. During the intertrial interval, only the houselight was illuminated.

Cold exposure. The rats were placed into the chamber $1 \mathrm{~h}$ before the start of each session. During this presession time, all lights in the chamber were off. At the end of $1 \mathrm{~h}$, the houselight was illuminated and the session started. The 1 -h presession placement in the chamber was in effect for all sessions. During all noncold sessions, the environmental chamber was programmed at $23^{\circ} \mathrm{C}$. The subjects were exposed to $2^{\circ} \mathrm{C}$ once every 2 weeks. The spacing of one cold exposure every other week served to maintain performance accuracy at a high level and to prevent the animals from developing a physiological adaptation to cold stress. All exposures were performed between the hours of 0730 and 1200, EST. Each rat received two exposures to the cold stress in each of the drug conditions.

Glucose administration. Glucose $(10-500 \mathrm{mg} / \mathrm{kg})$ or saline was given $1 \mathrm{~h}$ before a 75-min session in which the rats performed the DMTS task. These were administered on Tuesdays and Fridays. During the other days of the week, the subjects performed on the DMTS baseline. Each condition was run twice for each rat. The drug- and cold-exposure conditions were administered in a mixed sequence. Glucose and saline were administered into the peritoneal cavity (i.p.).

\section{Data Analysis}

Overall group differences were determined by a repeated measures analysis of variance (ANOVA). Pairwise comparisons were accomplished using a least squared means test using the error term from the appropriate ANOVA. The data from each of the two exposures to the respective treatment conditions were averaged for analysis.

\section{RESULTS}

Figure 1 shows the three performance measures during exposure to $23^{\circ} \mathrm{C}$ air. The right panel depicts mean response accuracy performance at each of the five delay intervals as a function of glucose and saline administration. The graph in the upper left shows the total number 
TRIALS COMPLETED

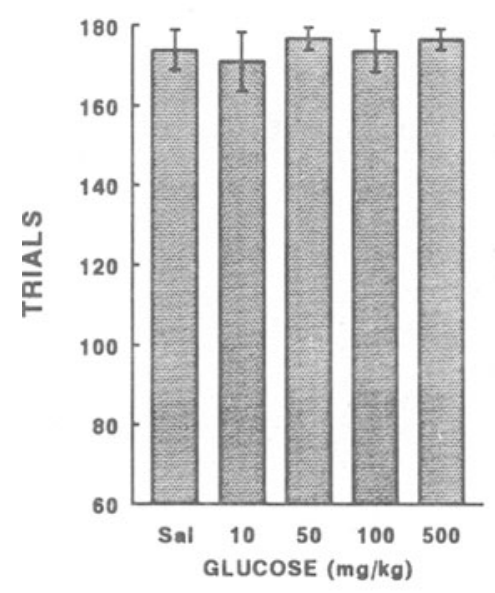

SAMPLE ACCURACY

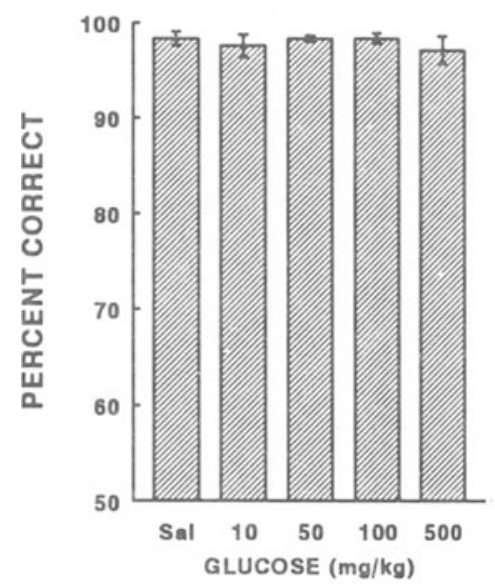

$23^{\circ} \mathrm{C}$

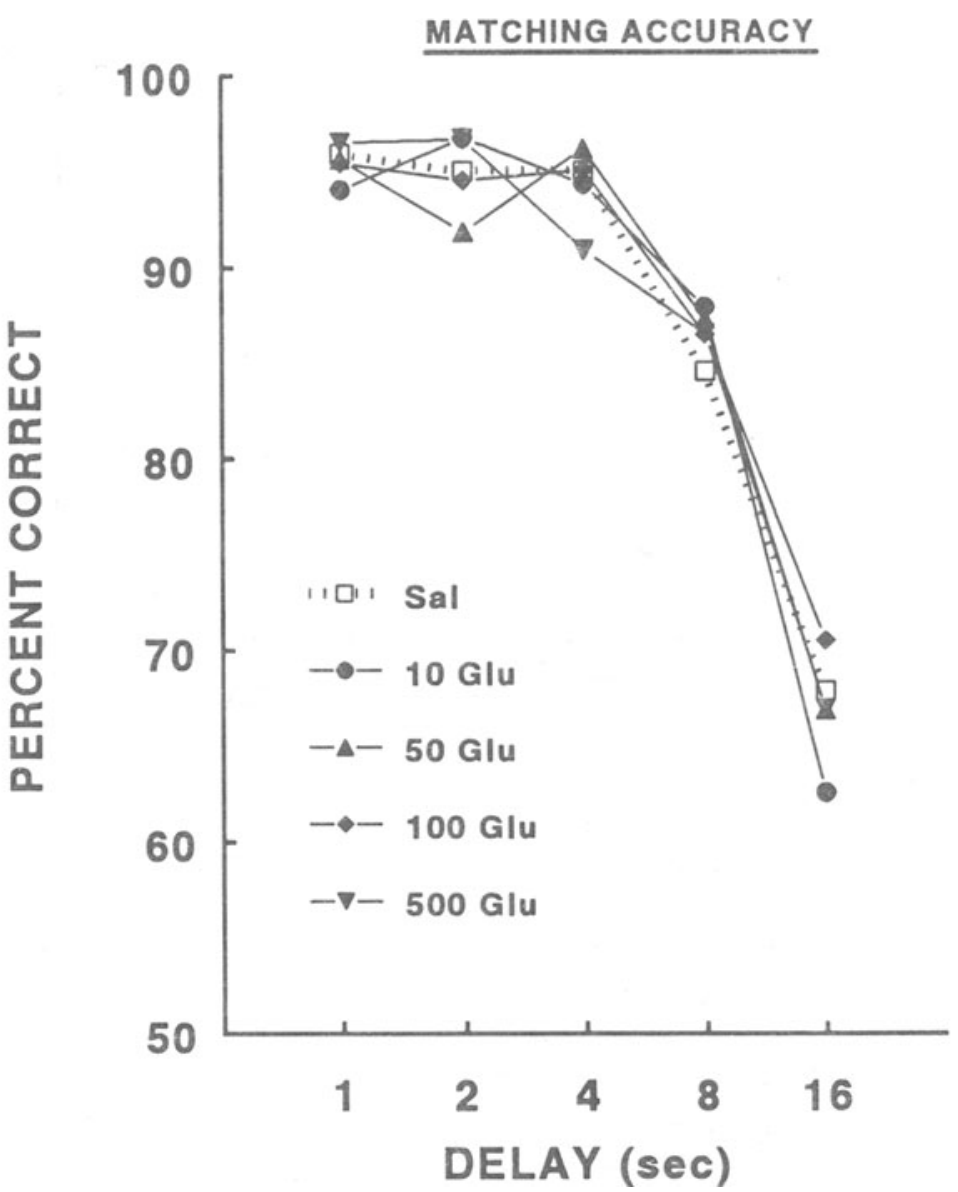

Figure 1. Right panel: Matching response accuracy on the delayed matching-to-sample (DMTS) procedure during exposure to an ambient temperature of $23^{\circ} \mathrm{C}$. Glucose (Glu) or saline (Sal) was administered (i.p.) 60 min prior to the beginning of the test session. Sessions were terminated after completion of 180 trials or $75 \mathrm{~min}$, whichever occurred first. Trials completed are depicted in the upper left panel. Sample accuracy, the ability to correctly discriminate the illuminated stimulus at the beginning of each trial, is depicted in the lower left panel.

of trials completed, and the graph below it depicts overall sample accuracy. Figure 2 depicts these same measures during exposure to the cold stress. In each of these graphs, the saline control data when the rats were exposed to $23^{\circ} \mathrm{C}$ are included for comparison.

\section{Matching Accuracy}

Overall analysis using a three-way ANOVA [temperature $(2) \times$ dose $(4) \times$ delay $(5)]$ indicated a significant main effect of temperature $[F(1,2)=62.07, p<.02]$ and delay $[F(4,8)=43.07, p<.02]$. The main effect of dose was not significant $[F(4,8)=2.43, p>.1]$. The interactions between temperature and dose $[F(4,8)=$ $5.86]$ and temperature and delay $[F(4,8)=9.78]$ were both highly significant $(p s<.01)$. However, the dose $x$ delay interaction $[F(16,32)=1.04]$ and the three-way interaction between temperature, dose, and delay $[F(16,32)$ $=1.33]$ were not significant. None of the pairwise comparisons revealed significant differences between any of the injection conditions at any delay when the rats performed at $23^{\circ} \mathrm{C}$.

Analysis of individual differences between the conditions reflected in Figure 2 revealed that exposure to $2^{\circ} \mathrm{C}$ significantly decreased matching accuracy at all delays in the condition pretreated with saline compared with the corresponding exposure to $23^{\circ} \mathrm{C}$. At the $1-\mathrm{sec}$ delay, the 10,100 , and $500 \mathrm{mg} / \mathrm{kg}$ doses of glucose completely blocked the cold-induced impairment in accuracy $(p s<$ 


\section{TRIALS COMPLETED}

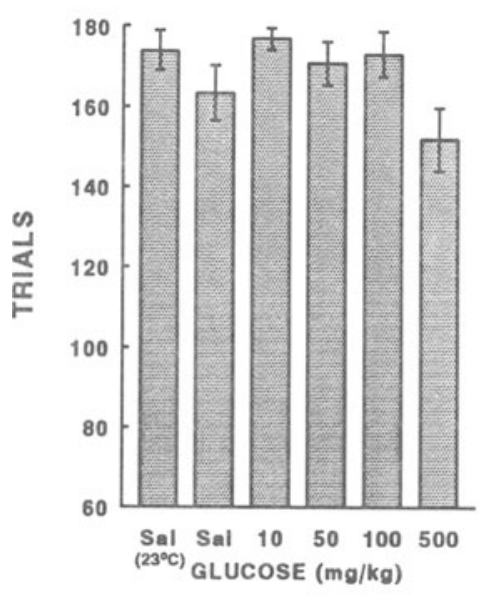

\section{SAMPLE ACCURACY}

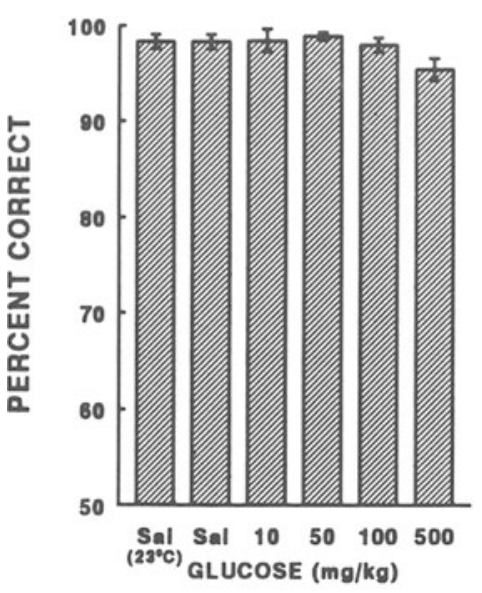

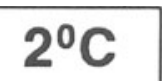

MATCHING ACCURACY

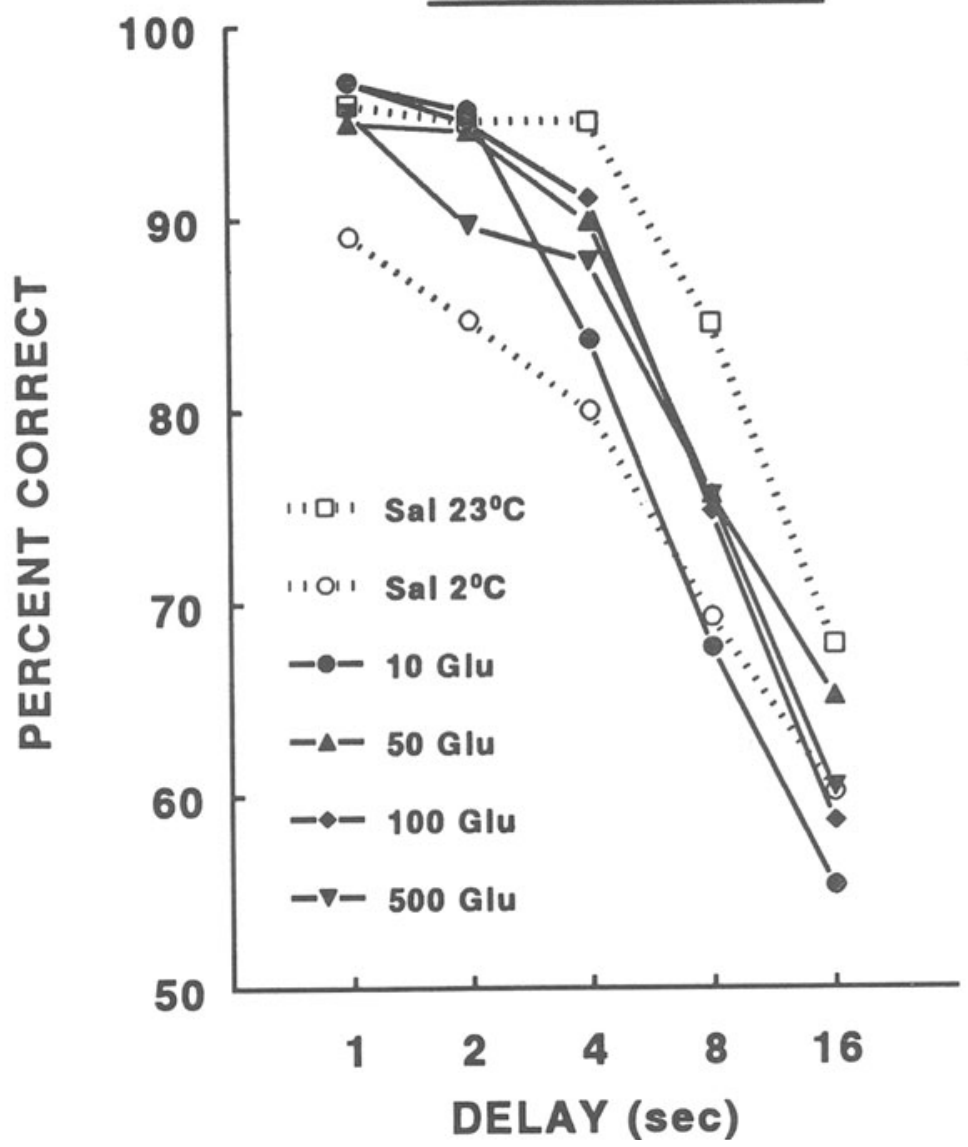

Figure 2. Right panel: Matching response accuracy on the delayed matching-to-sample (DMTS) procedure during exposure to an ambient temperature of $2^{\circ} \mathrm{C}$. Glucose (Glu) or saline (Sal) was administered (i.p.) 60 min prior to the beginning of the test session. Sessions were terminated after completion of 180 trials or $75 \mathrm{~min}$, whichever occurred first. Trials completed are depicted in the upper left panel. Sample accuracy, the ability to correctly discriminate the illuminated stimulus at the beginning of each trial, is depicted in the lower left panel. Rats performed the DMTS task $60 \mathrm{~min}$ after the exposure period began.

$.05)$; the $50 \mathrm{mg} / \mathrm{kg}$ dose was marginally significant ( $p=$ .06). Performance in the glucose conditions at the 1 -sec delay during exposure to $2^{\circ} \mathrm{C}$ was not significantly different from that of the same treatment groups tested at $23^{\circ} \mathrm{C}$. With the $2-\mathrm{sec}$ delay, only the $500 \mathrm{mg} / \mathrm{kg}$ glucose was ineffective in improving performance. At the $4 \mathrm{sec}$ delay interval, $10 \mathrm{mg} / \mathrm{kg}$ of glucose did not significantly improve the cold-induced matching accuracy deficit. However, all of the higher doses of glucose significantly attenuated the decrease in matching accuracy at the 4-sec delay resulting from exposure to cold stress. Glucose did not significantly improve performance at the 8- or 16-sec delays.

\section{Sample Accuracy}

Analysis of the accuracy in correctly identifying the illuminated sample stimulus at the beginning of the trial indicated no effect of cold stress $[F(1,2)=0.51]$ and no effect of glucose $[F(4,8)=2.25]$. Similarly, the temperature $\times$ dose interaction was nonsignificant $[F(4,8)=1.62]$.

\section{Trials Completed}

There was a highly significant effect of temperature on the number of trials completed $[F(1,2)=20.32, p<.05]$, however, neither the main effect of glucose $[F(4,8)=$ $2.89]$ nor the dose $\times$ temperature interaction $[F(4,8)]$ was significant. Pairwise analysis applied to the data indicated 
that, when in the cold-exposure condition, rats given $500 \mathrm{mg} / \mathrm{kg}$ glucose completed fewer trials than the $23^{\circ} \mathrm{C}$ saline control; there were no significant differences between the $500 \mathrm{mg} / \mathrm{kg}$ glucose conditions tested in either $23^{\circ} \mathrm{C}$ or $2^{\circ} \mathrm{C}$ ambient air. The $2^{\circ} \mathrm{C}$ saline condition was also slightly decreased relative to the normothermic saline condition; however, this did not reach statistical significance.

\section{DISCUSSION}

The results of this experiment indicate that administration of glucose can partially alleviate a cold-induced deficit in working memory. Under ambient cold stress conditions that produced a downward shift in the delay gradient in matching accuracy, the effects of glucose were both doseand delay-dependent. With a 1- and 2-sec delay between presentation of the sample and test stimuli, doses of glucose between 10 and $100 \mathrm{mg} / \mathrm{kg}$ completely blocked the cold-induced impairment in accuracy. At the 4-sec delay, all but the lowest glucose dose alleviated the decrease in matching accuracy resulting from exposure to ambient cold air. Glucose did not alleviate the cold-induced decrement with 8- and 16-sec delays. During cold stress, administration of $500 \mathrm{mg} / \mathrm{kg}$ glucose improved accuracy at the 1-sec delay. However, the high dose of glucose was associated with a decrease in sample accuracy and number of trials completed, indicating that this dose may have produced nonspecific motor or motivational effects when it was given during exposure to $2^{\circ} \mathrm{C}$. With the exception of slight changes in sample accuracy, $500 \mathrm{mg} / \mathrm{kg}$ glucose did not produce systematic decreases in accuracy when administered at the normothermic temperature of $23^{\circ} \mathrm{C}$. Since doses lower than $500 \mathrm{mg} / \mathrm{kg}$ improved accuracy but did not affect performance on any other measure, the data indicate that doses of glucose under $500 \mathrm{mg} / \mathrm{kg}$ enhanced matching accuracy during cold stress without affecting some motivational component required to perform the appetitive task.

Despite several reports of improved performance in nonamnestic subjects with glucose administration (Means \& Fernandez, 1992; Messier \& Destrade, 1988; Packard \& White, 1990), in the present study there was no detectable improvement in matching accuracy with glucose administration when the rats performed in an ambient temperature of $23^{\circ} \mathrm{C}$. This is likely due to the fact that the rats were at an asymptotic level of performance, especially at the short delay intervals in which glucose appeared to be most effective in those exposed to cold stress.

Although the alleviation of the cold-induced decrement in matching accuracy by glucose was specific to short delays, the effects seen here are nevertheless consistent with previous studies demonstrating glucose-induced alleviation of short- or long-term memory impaired by a variety of means. The memory-enhancing effects of glucose have generally indicated that doses ranging from 50 to $250 \mathrm{mg} / \mathrm{kg}$ are most efficacious (see Gold, 1991), although some researchers have reported effects with 2-4 g/kg (Messier \& Destrade, 1988; Packard \& White,
1990). Gold and colleagues have demonstrated that, for both humans and rodents, the optimal blood level of glucose in terms of memory improvement is $120-160 \mathrm{mg} / \mathrm{dL}$ (Hall \& Gold, 1986; Parsons \& Gold, 1992). Data from the present study indicate that even a relatively low dose of $10 \mathrm{mg} / \mathrm{kg}$ glucose is effective in enhancing matching accuracy during cold stress. While blood glucose levels were not obtained in the present study, it is known that exposure to cold stress increases systemic glucose (BorgAndersson, Ekström, \& Birkhed, 1992). Thus, the efficacy of the $10 \mathrm{mg} / \mathrm{kg}$ dose and the overall effects of the $500 \mathrm{mg} / \mathrm{kg}$ dose on several measures may be due to the cold stress producing a leftward shift in a glucose dose response curve. However, the fact that cold exposure, which may increase blood glucose levels, consistently impairs but does not improve working memory, suggests that glucose modulation of the decrement is more complex than a simple additive effect.

In previous studies in our laboratory, we have observed that moderate cold stress produces two basic patterns in terms of matching accuracy across the delays on the DMTS task. Using three delay values of 2, 8, and $16 \mathrm{sec}$, Thomas et al. (1991) demonstrated that cold stress decreased accuracy at the 8- and 16-sec delays, but not at 2 sec. Since matching accuracy at the 2 -sec delay was near optimal and was unaffected by the cold stress, the greater decline in the slope of the delay gradient suggested that cold stress specifically impaired the retention of information in working memory without decreasing the ability to encode the initial sample stimulus (Bushnell, 1990). However, in a subsequent study we demonstrated that cold stress produced a decrease in the $y$-intercept and an increase in the slope function of the delay gradient such that there was a decrement in matching accuracy performance at all of the delays (Ahlers et al., 1991). In this study, it was presumed that encoding was at least partially impaired by the cold stress, since there was a decrement in accuracy across all of the delays without an obvious effect on the slope of the delay gradient. It appeared that glucose improved the cold-induced deficit in encoding by improving performance at the shorter delay intervals. In order to unequivocally determine whether glucose administration can modulate retention of information in working memory during cold stress, further studies are needed to examine its effects in situations in which encoding is not impaired.

The encoding deficit observed here when the rats performed the DMTS task in the cold is similar to the effects of scopolamine on similar tests of working memory in rats (Bushnell, 1990). This is important, because one of the proposed mechanisms for glucose effects on memory is an increase of ACh via glucose acting as a precursor to acetyl CoA (Gold, 1991; Messier, Durkin, Mrabet, \& Destrade, 1991). However, another possible mechanism for glucose enhancement of matching accuracy during cold stress may stem from a direct increase in glucose-mediated metabolism in specific brain regions. Decreased glucose utilization in the brain regions as- 
sociated with working memory has been correlated with impaired performance (Gage, Kelly, \& Bjorklund, 1984). If temperature changes in regions such as the hippocampus reflect metabolic activity and glucose uptake, then our observation that the cold-induced impairment of working memory is associated with a $1^{\circ} \mathrm{C}$ decrease in hippocampal temperature (Ahlers et al., 1991) may be pertinent to the effects of glucose on the cold deficit. Increased glucose availability could possibly diminish a reduction in brain temperature (metabolic activity?) and thus attenuate the cold-induced decrement.

In summary, the administration of glucose alleviated a cold-induced deficit in working memory with greater efficacy at short versus long delay intervals. Generally speaking, glucose had no effect on performance when administered during $23^{\circ} \mathrm{C}$. Because glucose administration was most effective in improving matching accuracy at the shorter delays during cold stress, it appears that glucose enhanced the encoding of information into working memory, an observation consistent with the effects of glucose using other procedures. Recent data from our laboratory, using a repeated acquisition procedure in which rats were required to learn a novel response sequence within a test session, support the observation that glucose preferentially enhances encoding (Schrot \& Ahlers, 1993). In this situation, in which the acquisition of the response sequence is protracted over multiple trials, glucose not only improves performance during cold stress, but also improves acquisition during exposure to $23^{\circ} \mathrm{C}$.

\section{REFERENCES}

Ahlers, S. T., Thomas, J. R., \& Berkey, D. L. (1991). Hippocampal and body temperature changes in rats during delayed matching-tosample performance in a cold environment. Physiology \& Behavior, 50, 1013-1018.

Borg-Andersson, A., Ekström, J., \& Birkhed, D. (1992). Glucose in human parotid saliva in response to cold stress. Acta Physiology Scandinavia, 146, 238-284.

BushnelL, P. J. (1990). Modelling working and reference memory in rats: Effects of scopolamine on delayed matching-to-position. $B e$ havioral Pharmacology, 1, 419-427.

Destrade, C., Messier, C., Bontempi, B., Sif, J., \& Jaffard, R. (1992). Investigations into time-dependent metabolic changes during memory processing in the mouse brain using $\left({ }^{14} \mathrm{C}\right)$ deoxyglucose and $\left({ }^{14} \mathrm{C}\right)$-glucose. In F. Gonzalez-Lima (Ed.), Advances in metabolic map- ping techniques for brain imaging of behavioral and learning functions (pp. 389-407). Dordrecht, The Netherlands: Kluver Academic Publishers.

Gage, F. H., Kelly, P. A. T., \& Bjorklund, A. (1984). Regional changes in brain glucose metabolism reflect cognitive impairments in aged rats. Journal of Neuroscience, 4, 2856-2865.

Gold, P. E. (1991). An integrated memory system: From blood to brain. In R. C. A. Frederickson, J. L. McGaugh, \& D. L. Felten (Eds.), Peripheral signaling of the brain: Role in neural-immune interactions and learning and memory (pp. 391-419). Lewiston, NY: Hogrefe \& Huber.

HALl J. L., \& Gold, P. E. (1986). The effects of training, epinephrine, and glucose injections on plasma glucose levels in rats. Behavioral \& Neural Biology, 46, 156-167.

Means, L. W., \& Fernandez, T. J. (1992). Daily glucose injections facilitate performance of a win-stay water-escape working memory task in mice. Behavioral Neuroscience, 106, 345-350.

MESSIER, C., \& DESTRADE, C. (1988). Improvement of memory for an operant response by post-training glucose in mice. Behavioural Brain Research, 31, 185-191.

Messier, C., Durkin, T., Mrabet, O., \& Destrade, C. (1991). Contribution of hippocampal acetylcholine synthesis to the memoryimproving action of glucose. In R. C. A. Frederickson, J. L. McGaugh, \& D. L. Felten (Eds.), Peripheral signaling of the brain: Role in neural-immune interactions and leaming and memory (pp. 473477). Lewiston, NY: Hogrefe \& Huber.

Packard, M. G., \& White, N. M. (1990). Effect of posttraining injections of glucose on acquisition of two appetitive learning tasks. Psychobiology, 18, 282-286.

Parsons, M. W., \& Gold, P. E. (1992). Glucose enhancement of memory in elderly humans: An inverted-U dose-response curve. Neurobiology of Aging, 13, 401-404

Ragozzino, M. E., \& Gold, P. E. (1991). Glucose effects on mecamylamine-induced memory deficits and decreases in locomotor activity in mice. Behavioral \& Neural Biology, 56, 271-282.

SCHROT, J., \& AHLERS, S. T. (1993). Glucose restores the acquisition of response chains disrupted by cold air exposure in rats. Manuscript submitted for publication.

Stone, W. S., Walser, B., Gold, S. D., \& Gold, P. E. (1991). Scopolamine- and morphine-induced impairments of spontaneous alternation performance in mice: Reversal with glucose and with cholinergic and adrenergic agonists. Behavioral Neuroscience, 105 , 264-271.

Thomas, J. R., Ahlers, S. T., House J. F., \& Schrot, J. (1989). Repeated exposure to moderate cold impairs matching-to-sample performance. Aviation, Space \& Environmental Medicine, 60, 1063-1067.

Thomas, J. R., Ahlers, S. T., \& SChrot, J. (1991). Cold-induced impairment of delayed matching in rats. Behavioral \& Neural Biology, 55, 19-30.

(Manuscript received December 15, 1992 revision accepted for publication March 3, 1993.) 